\title{
A Rare Case of Superficial Parotid Lipoma
}

Jawad Hasnaoui*, Said Anajar, Lyoubi hicham, Zakaria chafiki, Reda Abada, Sami Rouadi, Mohammed Roubal and Mohammed Mahtar

Department of ENT, University Hospital Centre IBN ROCHD, North Africa

Submission: April 04, 2017; Published: April 11, 2017

*Corresponding author: Jawad Hasnaoui, ENT Department, Face and Neck Surgery, Hospital August, 20'1953, University Hospital Centre IBN ROCHD, Casablanca, Morrocco, 6, Street lahssen ELAARJOUN quartier des hopitaux, Casablanca, Morroco, North Africa,

Email: jawad.hasnaoui86@gmail.com

Abstract

The occurrence of lipomas in the parotid gland is extremely rare, and impossible to differentiate clinically. The entity's incidence is about $0.6-4.4 \%$ of parotid gland mass lesions and history of previous trauma in the area is the most common pathophysiological mechanism described. We present a case of a 54-year-old man with parotid lipoma treated with superficial parotidectomy with facial nerve preservation. The diagnosis of parotid lipoma is based on clinical, radiological and histological arguments. CT and/or MRI evaluation of the head and neck is very important, although histological confirmation is critical.

Keywords: Parotid gland; Lipoma; Superficial parotidectomy

\section{Introduction}

Lipomas are common mesenchymal tumors consisting of fat, although the occurrence of such in the parotid gland is extremely. They represent between 0.6 and $4.4 \%$ of the benign parotid tumors [1]. They are seldom considered in the initial differential diagnosis of a parotid mass and are often mistaken for other parotid neoplasms [2]. We present a case of a 54-year-old man with parotid lipoma treated with superficial parotidectomy through our case, we describe the different steps that led to the diagnosis of liposarcoma, as well as a review of the literature.

\section{Case Report}

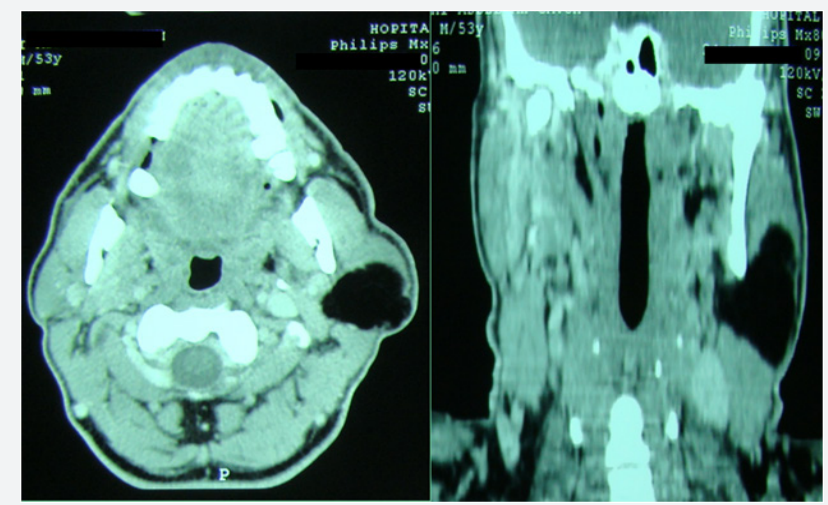

Figure 1: An axial and coronal image from the CT scan shows a large intraparotid mass of fat density measured $60 \times 55 \times 32 \mathrm{~mm}$.
A 54-year-old North african man presented with a 2 years history of a slowly growing painless mass in the left pre-auricular area. The clinical examination revealed a $5 \mathrm{~cm}$ soft, mobile, nonfluctuant and regular mass within the left parotid gland with normal overlying skin; without any palpable adenopathy or clinical signs of facial paralysis. The radiological examination (CT) revealed a low-density regular solid lesion limited in the superficial lobe of the parotid which measured $6 \times 5,5 \times 3,2$ $\mathrm{cm}$, no cervical adenopathy was found (Figure 1). The imaging characteristics implied a lipomatous benign tumor.

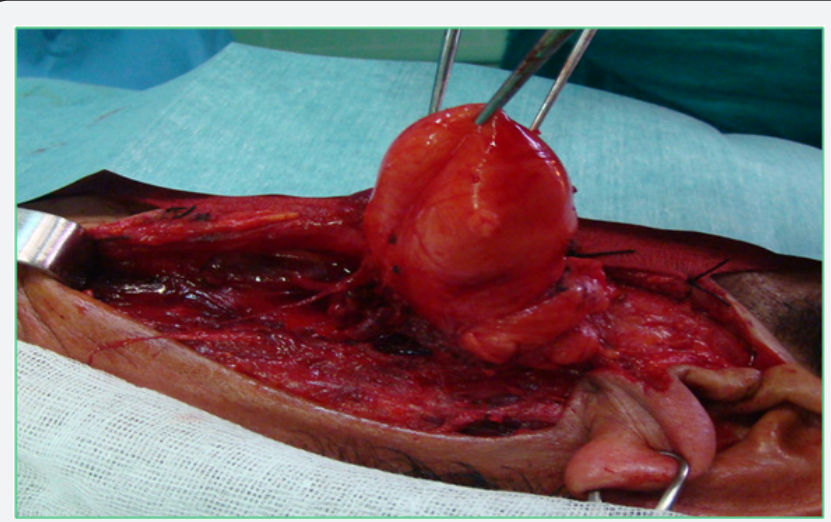

Figure 2: Intra-operative inspection revealed a regular lipomatous mass. 
The patient underwent a superficial parotidectomy with facial nerve preservation. The tumour was excised utilising a cervical-parotid approach. The lower pole of the parotid was dissecting from the anterior margin of the sternocleidomastoid muscle; a yellowish mass appears at the lower pole of the superficial lobe parotid surrounded with a smooth intact capsule which measured $6 \times 6 \times 3 \mathrm{~cm}$ (Figure 2). The excision was easily performed according to a cleavage plan. The post-operative follow-up was simple without facial paralysis Pathological examination of the mass found a well differentiated adipose tissue without cellular atypies surrounded by a fibrous capsule confirming the diagnosis of lipoma (Figure 3). The patient had no recurrence after 6 months of follow up.

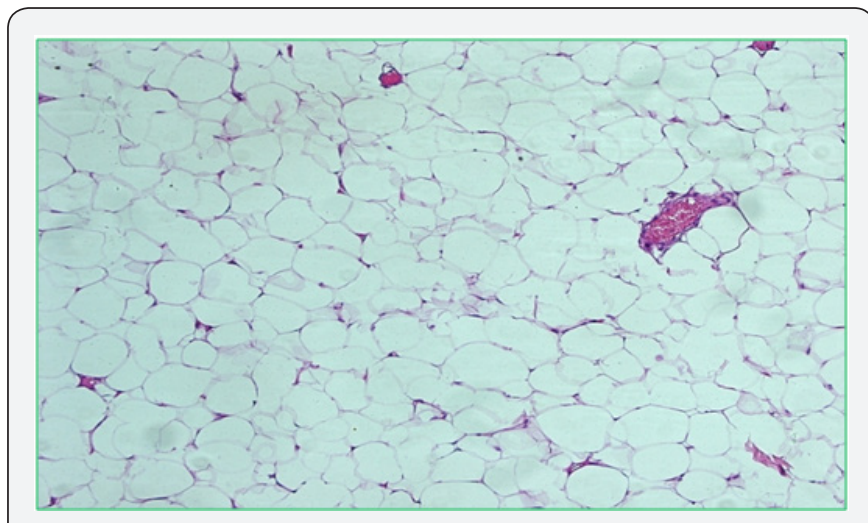

Figure 3: Diffuse lipomatosis demonstrating mature adipocytes infiltrating into and replacing the salivary gland parenchyma.

\section{Discussion}

Lipomatous lesions of the parotid gland are rare and are seldom considered in the initial diagnosis of a parotid swelling. Previous reports have suggested an aggregate frequency of $1.2 \%$ of parotid tumors, although the frequency in individual series has varied from $0.6 \%$ to $4.4 \%[1,2]$. Clinical diagnosis of parotid lipoma is very difficult. There is no clinical sign to distinguish of the other benign tumors of the parotid gland. They are In general asymptomatic except the deformation of the preauricular area. When they become voluminous, fleeting pain are described, probably related to tensions in the parotid region with displacing of the tonsils, larynx and lateral pharyngeal wall. Exceptionally, in an atypical case of superficial parotid lipoma, segmental facial paralysis was noted [3].

Imaging modalities and especially CT scan and MRI can achieve high accuracy in the preoperative diagnosis [4], giving valuable information for the malignant potential of the lesion and the exact location, which helps for the surgical strategy design. The presence of a well-encapsulated mass on CT with a density typically of -50 to -150 Hounsfield units oriented towards the diagnosis of lipoma. However this aspect is not pathognomonic and can be confused with a parotid tuberculous abscess.
MRI remains the exam of choice with greater sensitivity and specificity; It gives a precise localization of the tumor thanks to high tissue contrasts and orientates its nature without however replacing a formal histological diagnosis that only the surgery will bring [5]. Histopathologically and according to the amount and distribution of adipose tissue and epithelial component [6], tumours are categorized into three groups: ordinary lipoma, which is identical to soft tissue lipoma, oncocytic lipoadenoma, which consists of oncocytes with variable fat, and nononcocytic sialolipoma. The presence of a thin fibrous capsule around the lipoma is essential to distinguish the lesion from a simple fat aggregation.

Surgical treatment is based on a superficial parotidectomy with dissection of the facial nerve [7]. According to the authors, the rate of postoperative facial paralysis varies from 8 to $65 \%$ in the surgery of the benign tumors of the parotid gland [7]; this rate increases to $80 \%$ for the deep lobe lipomas [8]. Other therapeutic approaches are enucleation or tumorectomy with a healthy tissue margin but neglected because the risk of recurrence is very important. The rate of recurrence of intraparotid lipomas, all locations and all techniques combined, is of the order of $5 \%$ [7].

\section{Conclusion}

Parotid lipoma is a benign parotid pathology, which should be considered in the differential diagnosis of gland's mass lesions and clinical suspicion combined with appropriate imaging, without the aid of preoperative biopsy leads to efficient diagnosis. Meticulous surgical excision should be performed to avoid disturbing adverse events.

\section{References}

1. Copcu E, Sivrioglu NS (2003) Posttraumatic lipoma: analysis of 10 cases and explanation of possible mechanisms. Dermatol Surg 29(3): 215-220.

2. Srinivasan V, Ganesan S, Premachandra DJ (1996) Lipoma of the parotid gland presenting with facial palsy. J Laryngol Otol 110: 93-95.

3. Hohlweg-Majert B, Metzger MC, Dueker J, Schupp W, Schulze D (2007) Salivary gland lipomas: ultrasonographic and magnetic resonance imaging. J Craniofac Surg 18(6):1464-1466.

4. Agaimy A, Ihrler S, Märkl B, Lell M, Zenk J, et al. (2013) Lipomatous salivary gland tumors: a series of 31 cases spanning their morphologic spectrum with emphasis on sialolipoma and oncocytic lipoadenoma. Am J Surg Pathol 37:128-137.

5. Fakhry N, Michel J, Varoquaux A, Antonini F, Santini L, et al. (2012) Is surgical excision of lipomas arising from the parotid gland systematically required? Eur Arch Otorhinolaryngol 269(7): 18391844.

6. Dispenza F, De Stefano A, Romano G, Mazzoni A (2008) Posttraumaticlipoma of the parotid gland: case report. Acta Otorhinolaryngol Ital 28(2): 87-88.

7. Ozcan C, Unal M, Talas D, Gorur K (2002) Deep lobe parotid gland lipoma. J Oral Maxillofac Surg 60(4): 449-450. 
(C) This work is licensed under Creative

BY DOI: $10.19080 /$ GJO 2017.06 .555692

\section{Your next submission with Juniper Publishers} will reach you the below assets

- Quality Editorial service

- Swift Peer Review

- Reprints availability

- E-prints Service

- Manuscript Podcast for convenient understanding

- Global attainment for your research

- Manuscript accessibility in different formats

( Pdf, E-pub, Full Text, Audio)

- Unceasing customer service

Track the below URL for one-step submission https://juniperpublishers.com/online-submission.php 